\title{
Manejo com inseticidas visando o controle de percevejo marrom na soja intacta
}

\author{
Francisco de Carvalho Ribeiro ${ }^{1}$, Francileia de Sousa Rocha ${ }^{2}$, Eduardo Andrea Lemus \\ Erasmo $^{3}$, Edilson Pereira de Matos ${ }^{3}$, Sergio José da Costa ${ }^{4}$ \\ ${ }^{1}$ Universidade Federal do Tocantins - UFT, Campus de Gurupi, Gurupi, Tocantins, Brasil. E-mail: franciscocr@uft.edu.br, \\ ${ }^{2}$ Universidade Federal do Tocantins - UFT, Campus de Porto Nacional, Porto Nacional, Tocantins., Brasil. E-mail: \\ francileia.sousar@gmail.com \\ ${ }^{3}$ Universidade Federal do Tocantins, Campus de Palmas, Palmas,Tocantins, Brasil. E-mail: erasmolemus@uft.edu.br, \\ edilson.matos@syngenta.com \\ ${ }^{4}$ Instituto Federal de Educação, Ciência e Tecnologia do Tocantins, Campus de Gurupi, Gurupi, Tocantins, Brasil. E-mail: \\ sergiojose@ifto.edu.br
}

Recebido: 15/05/2016; Aceito: 16/06/2016.

\section{RESUMO}

Ao longo dos anos, verificou-se grandes mudanças no sistema de produção de soja no Brasil. O percevejo-marrom (Euschistus heros) é uma praga-chave da cultura da soja. É a espécie mais abundante do complexo de percevejos apresentando-se em predominância no estado do Tocantins e em grande parte das regiões dos cerrados produtoras de soja. Objetivou-se com esse trabalho avaliar a eficiência de diferentes inseticidas utilizados no manejo de Euschistus heros na cultura da soja intacta. O experimento foi conduzido no ano agrícola 2014/2015 em condições de campo na Fazenda Pedrinha, situada no município de Porto Nacional, Tocantins. O delineamento experimental foi de blocos casualizados, constituído de seis tratamentos com quatro repetições. Realizou-se amostragens com 0 , 3, 7, 10 dias após aplicação, avaliando-se a eficiência de controle, porcentagem de dano causado por percevejo, massa de 1.000 grãos e produtividade de grãos. O inseticida Imidacloprido + Bifentrina foi superior na eficiência de controle e no efeito residual em relação aos demais. Todos os inseticidas aplicados promoveram um incremento em produtividade quando comparados à testemunha, observando uma menor porcentagem de dano causado por percevejo marrom.

Palavras-chave: Glycine max (L.) Merrill, Euschistus heros, inseto-praga.

\section{Management with insecticides targeting the brown stink bug control in intact soybean crop}

\section{ABSTRACT}

Over the years, there are large changes in the soybean production system in Brazil. The brown stink bug (Euschistus heros) is a key pest of soybean crop. It is the most abundant species of bedbugs' complex performing in predominance in the state of Tocantins and in most regions of producing closed soybean. The objective of this study was to evaluate the efficacy of different insecticides used in the management of Euschistus heros in the intact soybean crop. The experiment was conducted in the agricultural year 2014/2015 under field conditions in Farm Pedrinha, in the municipality of Porto Nacional, Tocantins, Brazil. The experimental design was a randomized block, the experiment consisted of six treatments with four replications. Sampling was carried out at 0, 3, 7, 10 days after application, and control efficiency, percentage of damage caused by bedbug, mass of 1.000 grains and grain yield were evaluated. The Imidacloprid + Bifenthrin insecticide resulted in greater efficiency of brown stink bug control and residual effect in relation to others. All insecticides applied promoted an increase in grain yield compared to a control, watching a smaller percentage of damage caused by brown stink bug.

Key words: Glycine max L., Euschistus heros, insect pest. 


\section{Introdução}

O percevejo marrom Euschistus heros (F.) (Hemiptera: Pentatomidae) é uma praga-chave da cultura de soja (Glycine max L.) em várias regiões do Brasil, principalmente nas de clima quente (GODOY et al., 2010). Predominante nas lavouras de soja nos diferentes estado do Brasil, esse inseto pode ocasionar danos irreversíveis à cultura, pois, para se alimentar, suga diretamente os grãos de soja, o que acarreta redução na produção e na qualidade das sementes (DEPIERI; PANIZZI, 2011; SILVA et al., 2012).

O percevejo marrom (E. heros) é a espécie mais abundante do complexo de percevejos em predominância no estado do Tocantins e em grande parte das regiões dos cerrados produtoras de soja. Os ovos do percevejo marrom são colocados sobre as folhas ou vagens e normalmente são dispostos em fileiras duplas. A eclosão ocorre após 3 a 7 dias, as ninfas possuem hábitos gregários, ou seja, permanecem próximas à postura, possuem coloração marrom escura e medem cerca de $2 \mathrm{~mm}$ de comprimento. O tempo de desenvolvimento de ninfas - período do ovo à fase adulta - tem duração média de 38,6 dias (SILVA et al., 2006)

No decorrer da safra da soja, o percevejo marrom normalmente passa por três gerações; após a colheita da soja os insetos se alimentam de hospedeiros alternativos, completam a quarta geração e após esta geração vão para o solo e entram em diapausa, abrigados de parasitóides e predadores embaixo da palhada. Durante este período, que dura cerca de sete meses, os insetos não se alimentam; conseguem sobreviver através das reservas de lipídios armazenadas (HOFFMANN-CAMPO et al., 2000).

Os percevejos podem colonizar a soja no final do período vegetativo (V6-V8), nessa época os percevejos saem da diapausa ou de hospedeiros alternativos. Desta forma a população tende a crescer provocando danos significativos no período de enchimento dos grãos (R5.1 - R6). Os danos causados pelos percevejos marrom são em maioria causadas pela forma jovem entre o terceiro e quinto instares. Devido à inserção do estilete, provocam redução no percentual germinativo das sementes e qualidade de grãos (CORRÊA-FERREIRA, 2005).

Ao longo dos anos, verificou-se grandes mudanças no sistema de produção de soja no Brasil. A chegada da tecnologia Intacta RR2 PRO ${ }^{\circledR}$, que associa a resistência ao herbicida glifosato com genes de proteção ao ataque de lagartas é uma ferramenta tecnológica que permitiu aumento na produtividade da soja. No entanto, o manejo de percevejos não difere para a soja convencional, soja RR e a soja intacta RR2 PRO ${ }^{\circledR}$. As cultivares de soja intactas não apresentam efeito de controle para todas as pragas primárias que causam prejuízos na cultura da soja nos diferentes períodos do seu desenvolvimento, destacando os percevejos sugadores de vagens e grãos (GUEDES et al., 2012).

Visando à diminuição dos prejuízos causados pelos percevejos, o controle químico tem sido a medida mais utilizada podendo ser realizado por meio de aplicações preventivas de inseticidas sintéticos (BUENO et al., 2013). No entanto, o uso contínuo dos mesmos ingredientes ativos, aplicação de inseticidas com largo espectro de ação no início do desenvolvimento da cultura e ineficiência na tecnologia de aplicação são fatores que podem contribuir para o aumento da população de percevejos e no surgimento de populações resistentes.

Cabe salientar que produtos à base de endosulfan e metamidofós foram retirados do mercado, por causarem grande impacto no ambiente e apresentarem baixa seletividade no manejo de insetos. Surgiram restrições no número de moléculas para o manejo de percevejos na cultura soja. No cenário atual, inseticidas pertencentes aos grupos químicos dos neonicotinóides, piretróides, carbamatos e organofosforados estão disponíveis e são recomendados para o manejo de sugadores da soja.

Diante disto, a necessidade de informações e conhecimento de inseticidas que ajudam no manejo de percevejos tem levado a continuidade de trabalhos visando testar novos produtos e/ou formulações para o controle destas pragas. Portanto, objetivou-se com esse trabalho avaliar a eficiência de diferentes inseticidas utilizados no manejo de Euschistus heros na cultura da soja intacta.

\section{Material e Métodos}

O experimento foi conduzido no ano agrícola 2014/2015 em condições de campo na Fazenda Pedrinha, situada no município de Porto Nacional - TO, localizada em latitude Sul de $10^{\circ} 34^{\prime} 17^{\prime \prime}$ e longitude Oeste $48^{\circ} 22^{\prime} 59^{\prime \prime}$ de Greenwich, em altitude de 255 metros. Os dados de precipitação pluvial e temperatura do ambiente observados durante a condução do experimento encontram-se na (Figura 1).

Antes da instalação do experimento, foi realizada a amostragem do solo, na camada de $0-20 \mathrm{~cm}$ de profundidade, a qual apresentou a seguinte composição química: $\mathrm{pH}$ em $\mathrm{CaCl}_{2}=5,25 ; \mathrm{M} . \mathrm{O}=24 \mathrm{~g} \mathrm{dm}^{-3} ; \mathrm{P}$ $\left(\right.$ Melich-1) $=5,03 \mathrm{mg} \mathrm{dm}{ }^{-3} ; \mathrm{Ca}=2,20 \mathrm{cmol}_{\mathrm{c}} \mathrm{dm}^{-3} ; \mathrm{Mg}=$ $0,80 \mathrm{cmol}_{\mathrm{c}} \mathrm{dm}^{-3} ; \mathrm{H}+\mathrm{Al}=1,70 \mathrm{cmol}_{\mathrm{c}} \mathrm{dm}^{-3} ; \mathrm{K}=0,13$ $\mathrm{cmol}_{\mathrm{c}} \mathrm{dm}^{-3} ; \mathrm{CTC}=5,31 \mathrm{cmol}_{\mathrm{c}} \mathrm{dm}^{-3} ; \mathrm{V} \%=64,30$.

A semeadura foi realizada em 12 de novembro de 2014, utilizando-se densidade de 18 sementes por metro linear e espaçamento de 0,50 metros entre linhas. A cultivar utilizada foi a CD 2820 IPRO.

Por ocasião da semeadura inoculou-se as sementes com estirpes de Bradyrhizobium japonicum, com a finalidade de se obter boa nodulação das raízes, 
garantindo o suprimento de nitrogênio à cultura. A adubação foi realizada no sulco semeadura plantio utilizando $500 \mathrm{~kg} \mathrm{ha}^{-1}$ da fórmula 05-25-15 (NPK). Aos 15 DAE (dias após a emergência) foi realizada uma adubação de cobertura com $90 \mathrm{~kg} \mathrm{ha}^{-1}$ de $\mathrm{KCl}$ (cloreto de potássio).

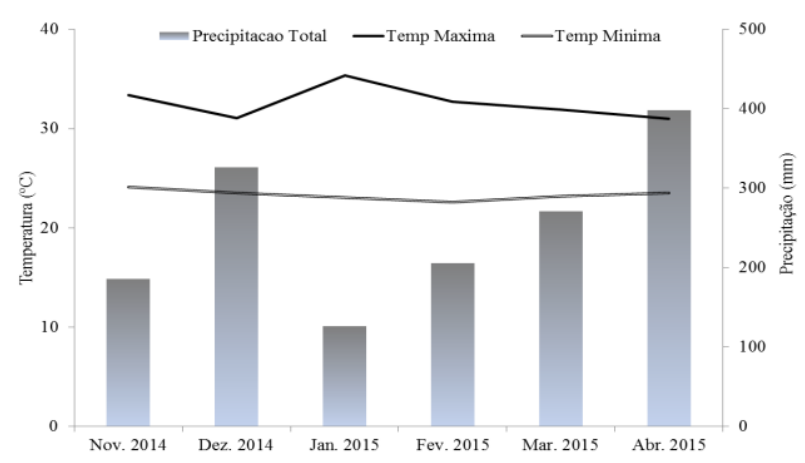

Figura 1. Precipitação pluvial e temperatura mensal, observadas no decorrer da fase experimental, em Porto Nacional - TO, safra 2014/2015. Fonte: INMET

Os tratos culturais para controle de plantas daninhas consistiram em aplicações dos herbicidas: SMetolacloro $\left(1,2 \mathrm{~L} \mathrm{ha}^{-1}\right)+$ Glifosato - sal de potássio $620\left(3,35 \mathrm{~L} \mathrm{ha}^{-1}\right)$ realizada em pré-emergência e do Glifosato - sal de potássio $620\left(2,0 \mathrm{~L} \mathrm{ha}^{-1}\right)$ realizado em pós-emergência no estádio vegetativo $\mathrm{V} 4$.

O manejo das doenças como a mancha alvo (Corynespora cassiicola) e antracnose (Colletotrichum truncatum) foi realizado com três aplicações de fungicidas: Azoxistrobina + Difenoconazol $\left(0,2 \mathrm{~L} \mathrm{ha}^{-1}+\right.$ $0,3 \mathrm{~L} \mathrm{ha}^{-1}$ e $0,5 \mathrm{~L} \mathrm{ha}^{-1}$ de óleo mineral recomendado pelo fabricante) no estádio vegetativo V8, Trifloxistrobina + Protioconazol $\left(0,4 \mathrm{~L} \mathrm{ha}^{-1}\right.$ e $0,3 \mathrm{~L} \mathrm{ha}^{-1}$ de éster metílico de óleo de soja recomendado pelo fabricante) no estádio reprodutivo R2 e Azoxistrobina + Benzovindiflupir $\left(0,2 \mathrm{~kg} \mathrm{ha}^{-1}\right.$ e $0,6 \mathrm{~L} \mathrm{ha}^{-1}$ de óleo mineral recomendado pelo fabricante) no estádio reprodutivo $\mathrm{R} 5$.

O delineamento experimental utilizado foi de blocos casualizados, o experimento foi constituído de seis tratamentos (Tabela 1) com quatro repetições. As unidades experimentais apresentavam 18 linhas de 12 metros de comprimento e espaçadas entre si com 0,50 metros. Totalizando $108 \mathrm{~m} 2$ a área de cada unidade experimental e $2.592 \mathrm{~m} 2$ a área total do experimento. Para área útil considerou-se as 2 linhas centrais de cada parcela, desprezando 3,5 metros nas extremidades de cada linha totalizando uma área útil de $5 \mathrm{~m} 2$ por parcela.

Durante a instalação do experimento o campo de soja encontrava-se com $100 \%$ dos grãos totalmente cheios dentro das vagens correspondendo ao estádio reprodutivo R6. As aplicações dos tratamentos foram realizadas em uma única vez, utilizando-se um pulverizador costal pressurizado a $\mathrm{CO}_{2}$, com pressão constante, munido de seis pontas XR 11002 BD, espaçadas de 0,5 metro e volume de calda de $150 \mathrm{~L} \mathrm{ha}^{-1}$. Durante a aplicação a umidade relativa do ar manteve-se em $78 \%$, temperatura em $29{ }^{\circ} \mathrm{C}$ e velocidade do vento variando de 2 a $3 \mathrm{~km} \mathrm{~h}^{-1}$.

Como critério avaliativo adotou-se a utilização de pano-de-batida $\left(0,5 \mathrm{~m}^{2}\right)$, contabilizando conjuntamente os percevejos adultos e ninfas grandes ( $3^{\circ}$ a $5^{\circ}$ instar). Foram realizadas 4 amostras por unidade experimental, sendo aos $0,3,7$ e 10 dias após a aplicação dos tratamentos (DAA). A eficiência de controle dos tratamentos foi calculada através da equação de Abbott (1925).

Tabela 1. Tratamentos aplicados na cultura da soja, cultivar CD 2820 IPRO, com respectivas doses. Porto Nacional - TO, 2015

\begin{tabular}{lccc}
\hline Tratamentos & P.C. $\left(\mathrm{L} \mathrm{ha}^{-1}\right)\left(\mathrm{Kg} \mathrm{ha}^{-1}\right)$ & $\mathrm{I}$. A $\left(\mathrm{g} \mathrm{ha}^{-1}\right)$ & $\begin{array}{c}\text { Época de } \\
\text { aplicação }\end{array}$ \\
\hline 1) Testemunha & $\mathrm{X}$ & $\mathrm{X}$ & $\mathrm{X}$ \\
2) Thiametoxam + Lambda-Cialotrina & 0,3 & $42,3+31,8$ & $\mathrm{R} 6$ \\
3) Imidacloprido + Bifentrina & 0,3 & $75+15$ & $\mathrm{R} 6$ \\
4) Acefato & 1,2 & 900 & $\mathrm{R} 6$ \\
5) Acefato & 1,0 & 750 & $\mathrm{R} 6$ \\
6) Lambda-Cialotrina & 0,2 & 10 & $\mathrm{R} 6$ \\
\hline
\end{tabular}

A colheita foi realizada dia 05 de março de 2015. Determinou-se as características agronômicas: massa de 1.000 grãos e produtividade da cultura da soja. A massa de 1.000 grãos foi obtida a partir de uma amostra correspondente a cada parcela onde a massa foi ajustada para umidade de $13 \%$. Quanto à produtividade foram pesados os grãos colhidos das plantas referentes às duas linhas centrais de 5 metros de cada parcela; as plantas foram submetidas à trilhagem mecânica, a massa foi corrigida para $13 \%$ de umidade e os valores convertidos para $\mathrm{kg} \mathrm{ha}^{-1}$. A análise de dano causado por percevejo foi realização através do teste de tetrazólio. Foram coletadas quatro sub amostras de 50 grãos de cada tratamento, conforme metodologia descrita por França 
Neto et al. (1998). Os grãos foram acondicionados entre duas folhas de papel germitest umedecidas com 2,5 vezes o seu peso com água destilada, na câmara Mangelsdorff regulada à temperatura de $25^{\circ} \mathrm{C}$, durante 16 horas. Após o acondicionamento, os grãos foram colocados na solução de 2,3,5-trifenil-cloreto-detetrazólio a $0,075 \%$ e armazenados à temperatura de 40 ${ }^{\circ} \mathrm{C}$ por 3 horas para o desenvolvimento da coloração. $\mathrm{O}$ resultado foi expresso em porcentagem de dano causado por percevejo.

As médias dos dados foram submetidas à análise de variância. Realizou-se a comparação das médias pelo teste de Tukey a $5 \%$ de probabilidade para todas as variáveis estudadas, utilizando-se o programa software SISVAR (FERREIRA, 2011).

\section{Resultados e Discussão}

Verificou-se efeito significativo para grande maioria das variáveis estudadas (Tabela 2). O inseto-praga percevejo marrom obteve sucesso no seu estabelecimento e promoveu populações na área experimental com níveis acima de dois percevejos por pano-de-batida suficiente para discriminar os tratamentos quanto à sua eficácia de controle.

De acordo com Bueno et al. (2013), para o monitoramento de percevejos na cultura da soja, durante a fase de produção de grãos, deve ser considerado como nível de controle a presença de dois percevejos adultos por pano-de-batida, para a produção de grãos.
$\mathrm{Na}$ avaliação de 3 DAA todos os inseticidas apresentaram diferenças significativas em relação à testemunha, porém não diferenciaram-se entre si (Tabela 3).

Os inseticidas Imidacloprido + Bifentrina e Thiametoxam + Lambda-Cialotrina, possibilitaram menores quantidades de percevejo marrom por pano-debatida e foram eficientes para controlar 78,99 e 76,47\% dos Euschistus heros presentes na área. Manter as infestações de percevejos baixas durante o período reprodutivo (R5-R6) da soja é de fundamental importância para manter a qualidade dos grãos.

$\mathrm{O}$ efeito negativo dos percevejos é maior quando se alimentam de soja no período de enchimento de grãos, pois são responsáveis por reduções no teor de óleo, aumento na percentagem de proteínas e ácidos graxos livres nos grãos, transmissão de patógenos e causadores de distúrbios fisiológicos como a retenção foliar (CORRÊA-FERREIRA, 2005).

Aos 7 DAA notou-se diferenças significativas dos tratamentos químicos em relação à testemunha exceto para o tratamento com o inseticida Acefato na dose de $1,0 \mathrm{~kg} \mathrm{ha}^{-1}$ (Tabela 3). Observou-se que todos os inseticidas aplicados alcançaram resultados inferiores a $80 \%$ de controle, o mínimo desejável (GAZZONI, 1988). Esses resultados estão relacionados à reinfestação da área experimental; o maior controle observado na avaliação de 7 DAA correspondeu a $72,45 \%$, para o tratamento que foi aplicado o inseticida (Imidacloprido + Bifentrina).

Tabela 2. Resumo da análise de variância das avaliações: 0, 3, 7 e 10 dias após a aplicação (DAA), dano causado por percevejo marrom (DP), massa de 1.000 grãos (MMG) e produtividade de grãos (P) dos diferentes tratamentos aplicados na cultivar de soja CD 2820 IPRO. Porto Nacional - TO, 2015.

\begin{tabular}{lcccccccc}
\hline \multirow{2}{*}{ Fonte de Variação } & \multicolumn{8}{c}{ QUADRADO MÉDIO } \\
\cline { 2 - 9 } & GL & 0 & 3 & 7 & 10 & DP $(\%)$ & MMG & P \\
\hline Tratamento & 5 & $0,04^{\mathrm{NS}}$ & $1,90^{*}$ & $3,50^{*}$ & $4,73^{*}$ & $49,10^{*}$ & $144,72^{*}$ & $236440,68^{*}$ \\
Bloco & 3 & 0,27 & 0,63 & 0,51 & 2,29 & 17,44 & 56,31 & 25048,25 \\
Resíduo & 15 & 0,06 & 1,86 & 0,46 & 0,23 & 12,67 & 17,53 & 36587,87 \\
\hline C.V (\%) & & 12,24 & 34,16 & 35,26 & 18,24 & 18,74 & 3,08 & 5,32 \\
\hline NS
\end{tabular}

NS não significativo $\mathrm{e} *$ significativo a $5 \%$ de probabilidade pelo teste $\mathrm{F}$.

Tabela 3. Número de percevejo marrom por pano-de-batida e eficiência de controle antes e após a aplicação (DAA), em função dos diferentes inseticidas aplicados na cultivar de soja CD 2820 IPRO. Porto Nacional - TO, 2015.

\begin{tabular}{|c|c|c|c|c|c|c|c|}
\hline \multirow{3}{*}{ Tratamentos } & \multicolumn{4}{|c|}{ Dias após a aplicação } & \multicolumn{3}{|c|}{ Dias após a aplicação } \\
\hline & 0 & 3 & 7 & 10 & 3 & 7 & 10 \\
\hline & \multicolumn{4}{|c|}{ Número de insetos em $0,5 \mathrm{~m}^{2}$} & \multicolumn{3}{|c|}{ Eficiência de controle (\%) } \\
\hline Testemunha & $1,94 \mathrm{a}$ & $2,38 \mathrm{~b}$ & $3,63 \mathrm{~b}$ & $4,63 \mathrm{c}$ & 0,00 & 0,00 & 0,00 \\
\hline Thiam. + Lambda-Cia. & $1,94 \mathrm{a}$ & $0,56 \mathrm{a}$ & $1,25 \mathrm{a}$ & $1,75 \mathrm{a}$ & 76,47 & 65,56 & 62,20 \\
\hline Imida. + Bifentrina & $2,13 \mathrm{a}$ & $0,50 \mathrm{a}$ & $1,00 \mathrm{a}$ & $1,69 \mathrm{a}$ & 78,99 & 72,45 & 63,50 \\
\hline Acefato $(1,2)$ & $2,00 \mathrm{a}$ & $0,88 \mathrm{a}$ & $1,81 \mathrm{a}$ & $2,44 \mathrm{ab}$ & 63,03 & 50,14 & 47,30 \\
\hline Acefato $(1,0)$ & $2,06 \mathrm{a}$ & $1,06 \mathrm{a}$ & $2,25 \mathrm{ab}$ & $3,00 \mathrm{~b}$ & 55,46 & 38,02 & 35,21 \\
\hline Lambda-Cialotrina & $2,19 \mathrm{a}$ & $0,81 \mathrm{a}$ & $1,67 \mathrm{a}$ & $2,31 \mathrm{a}$ & 65,97 & 53,99 & 50,11 \\
\hline Média & 2,04 & 1,03 & 1,94 & 2,64 & - & - & - \\
\hline
\end{tabular}

Médias seguidas da mesma letra na coluna, não diferem estatisticamente entre si pelo teste de Tukey a 5\% de probabilidade. 
A aplicação de um inseticida com dois grupos de ação diferentes (Neonicotinóides e piretróides) possibilitou maior desestabilização da população de percevejo marrom, quando comparado ao inseticida Acefato pertencente ao grupo do (Organofosforados), que apresenta um único local de ação. Reduzir a população de percevejos na fase final da cultura da soja (R6-R7) significa diminuir o número de vagens atacadas, aumentando a qualidade e o número de grãos íntegros, elevando a produtividade de grãos (DEPIERI; PANIZZI, 2011).

Com 10 DAA, observou-se que houve diferença significativa (Tabela 3). Embora as eficiências no controle de percevejo decresceram ao longo das avaliações. $\mathrm{O}$ inseticida Imidacloprido + Bifentrina foi superior a todos os tratamentos químicos, apresentando menor número de insetos por pano-de-batida no decorrer da avaliações, possibilitando a manutenção da população de insetos em níveis mais baixos. No entanto, os níveis de controle foram insatisfatórios para todos os tratamentos aplicados. Dessa forma, foi possível obter informações sobre o poder residual dos produtos testados em virtude da desestabilização da população de percevejos, destacando-se os inseticidas (Imidacloprido + Bifentrina) e (Thiametoxam + Lambda-Cialotrina) que obtiveram menores números de percevejos por pano-de-batida e promoveram controle de 63 e $62 \%$ aos 10 DAA respectivamente (Tabela 3 ).

Para variável dano causado por percevejos observouse que não houve diferença significativa. Os tratamentos Thiametoxam + Lambda-Cialotrina e Imidacloprido + Bifentrina obtiveram os melhores resultados quando comparados à testemunha apresentando $15,50 \%$ e $16,75 \%$ de dano causado por percevejo marrom (Tabela 4), no entanto, todas as aplicações dos referidos inseticidas promoveram um menor dano causado por percevejos possibilitando aumento na massa $\mathrm{e}$ produtividade final dos grãos. Avaliando o dano causado por percevejos, Villas Boas et al. (1990) observaram redução de $300 \mathrm{~kg} \mathrm{ha}^{-1}$ quando a soja foi submetida ao ataque de quatro percevejos $\mathrm{m}^{2}$, resultado superior foi obtido no presente trabalho, em que a testemunha apresentou um rendimento de $686,96 \mathrm{~kg} \mathrm{ha}^{-1}$; resultado inferior ao obtido no tratamento do inseticida
Imidacloprido + Bifentrina. Tal diferença de rendimento pode ser explicada pela permanência de populações variáveis de 1,94 a 4,63 percevejos marrom em 0,5 m² no tratamento testemunha.

Observando a massa de 1.000 grãos, notou-se diferença significativa, houve um aumento em função das aplicações dos inseticidas para todos os tratamentos quando comparados à testemunha (Tabela 4). A maior massa de 1.000 grãos (139,04 gramas) foi obtida no tratamento com inseticida Imidacloprido + Bifentrina, sendo superior ao tratamento testemunha $(123,83$ gramas). Este aumento mesmo sendo pequeno pode significar um aumento na produtividade de grãos, já que o peso do grão está diretamente ligado a este fator de produção. Infestações no período R5-R6 causaram reduções significativas no peso de sementes boas quando atacadas por dois ou quatro percevejos - em relação às plantas testemunhas, que variaram de 49,00 g a 46,30 g nas plantas com ataques de Euschistus heros (CORRÊA-FERREIRA, 2005).

Em relação à produtividade de grãos, apresentou diferença significativa. Observou-se aumento na produtividade em função das aplicações dos inseticidas para todos os tratamentos quando comparados à testemunha (Tabela 4). O tratamento Imidacloprido + Bifentrina resultou em uma maior produtividade $(3.825$ $\left.\mathrm{kg} \mathrm{ha}^{-1}\right)$. O segundo melhor resultado de produtividade (3.772 $\mathrm{kg} \mathrm{ha}{ }^{-1}$ ) foi verificado no tratamento Thiametoxam + Lambda-Cialotrina. $\mathrm{O}$ maior rendimento de grãos nos tratamentos que apresentaram as maiores massas médias de 1.000 grãos pode ser explicado, de acordo com Corrêa-Ferreira e Panizzi (1999) e Bonato (2000) pelo fato de que os menores índices de abortamento de legumes no início de enchimento dos grãos se dá em função da menor intensidade no ataque de percevejos, promovendo maior número de legumes por planta.

O controle propiciado pelos inseticidas possibilitou a diferenciação da testemunha, ressaltando a importância da adoção de medidas de controle no complexo de percevejos. Contudo é necessário avaliação de diferentes moléculas com mecanismos de ação distintos para ampliar a discussão quanto ao método empregado para manutenção do potencial de controle dos inseticidas.

Tabela 4. Dano causado por percevejo marrom (DP), massa de 1.000 grãos (MMG) e produtividade de grãos (P), em função dos diferentes inseticidas aplicados na cultivar de soja CD 2820 IPRO. Porto Nacional - TO, 2015.

\begin{tabular}{lccc}
\hline \multicolumn{1}{c}{ Tratamentos } & DP $(\%)$ & MMG $(\mathrm{g})$ & $\mathrm{P}\left(\mathrm{kg} \mathrm{ha}^{-1}\right)$ \\
\hline Testemunha & $25,50 \mathrm{a}$ & $123,83 \mathrm{a}$ & $3.138,40 \mathrm{a}$ \\
Thiametoxam + Lambda-Cialotrina & $15,50 \mathrm{~b}$ & $138,88 \mathrm{~b}$ & $3.772,44 \mathrm{~b}$ \\
Imidacloprido + Bifentrina & $16,75 \mathrm{~b}$ & $139,04 \mathrm{~b}$ & $3.825,36 \mathrm{~b}$ \\
Acefato (1,2) & $18,00 \mathrm{ab}$ & $138,16 \mathrm{~b}$ & $3.604,22 \mathrm{~b}$ \\
Acefato (1,0) & $18,50 \mathrm{ab}$ & $137,48 \mathrm{~b}$ & $3.586,51 \mathrm{~b}$ \\
Lambda-Cialotrina & $19,75 \mathrm{ab}$ & $138,87 \mathrm{~b}$ & $3.643,57 \mathrm{~b}$ \\
\hline Média & 19,00 & 136,04 & $3.595,05$ \\
\hline
\end{tabular}

Médias seguidas da mesma letra na coluna, não diferem estatisticamente entre si pelo teste de Tukey a 5\% de probabilidade. 


\section{Conclusões}

O inseticida Imidacloprido + Bifentrina foi superior na eficiência de controle e no efeito residual em relação aos demais.

Todos os inseticidas aplicados promoveram um incremento em produtividade quando comparados à testemunha, observando uma menor porcentagem de dano causado por percevejo marrom.

\section{Referências Bibliográficas}

ABBOTT, W.S. A method of computing the effectiveness of an inseticide. Journal of Economic Entomology, College Park, v. 18, n. 1, p. 265-267, 1925.

BONATO, R. B. Estresses em soja. Passo Fundo-RS: Embrapa Trigo, 2000. 254 p.

BUENO, A.F.; PAULA-MORAES, S.V.; GAZZONI, D.L.; POMARI, A.F. Economic thresholds in soybean-integrated pest management: old concepts, current adoption, and adequacy. Neotropical Entomology, Piracicaba-SP, v. 42, n. 5, p. 439-447, 2013. DOI: 10.1007/ s13744-013-0167-8.

CORRÊA-FERREIRA, B. S.; PANIZZI, A. R. Percevejos da soja e seu manejo. Londrina-PR: Embrapa Soja - CNPSO, 1999. 45 p. (Circular Técnica, 24).

CORRÊA-FERREIRA, B. S. Suscetibilidade da soja a percevejos na fase anterior ao desenvolvimento das vagens. Pesquisa Agropecuária Brasileira, Brasília-DF, v. 40, n. 11, p. 1067-1072, 2005. DOI: 10.1590/S0100204X2005001100003.

DEPIERI, R.; PANIZZI, A.R. Duration of feeding and superficial and in-depth damage to soybean seed by selected species of stink bugs (Heteroptera: Pentatomidae). Neotropical Entomology, Piracicaba-SP, v. 40, n. 2 p. 197-203, 2011. DOI: 10.1590/S1519-566X2011000200007.

FERREIRA, D. F. Sisvar: a computer statistical analysis system. Ciência \& Agrotecnologia, Lavras-MG, v. 35, n. 6, p. 1039-1042, 2011. DOI: 10.1590/S1413-
FRANÇA NETO, J.B.; KRZYZANOWSKI, F.C.; COSTA, N.P. O teste de tetrazólio em sementes de soja. LondrinaPR: Embrapa Soja - CNPSO, 1998. 72p. (Documentos, 116).

GAZZONI, D. L. Efeito de populações de percevejos na produtividade, qualidade da semente e características agronômicas da soja. Pesquisa Agropecuária Brasileira, Brasília-DF, v. 33, n. 8, p. 1229-1237, 1998.

GUEDES, J. V. C.; ARNEMANN, J.A.; STURMER, G.R.; MELO, A.A.; BIGOLIN, M.; PERINI, C.R.; SARI. B.G. Percevejos da soja: novos cenários, novo manejo. Revista Plantio Direto, Passo Fundo-RS, v. 12, n. 1, p. 24-30, 2012.

GODOY, K.B.; ÁVILA, C.J.; DUARTE, M.M.; ARCE, C.C.M. Parasitismo e sítios de diapausa de adultos do percevejo marrom, Euschistus heros na região da Grande Dourados, MS. Ciência Rural, Santa Maria-RS, v.40, n. 5, p. 1199-1202, 2010. DOI: 10.1590/ S0103-84782010005000074.

HOFFMANN-CAMPO, C. B.; MOSCARDI, F.; CORREAFERREIRA, B.S.; OLIVEIRA, L.J.; SOSA-GÓMEZ, D.R.; PANIZZI, A.R.; CORSO, I.C.; GAZZONI, D.L.; OLIVEIRA, E.B. Pragas da soja no Brasil e seu manejo integrado. Londrina-PR: Embrapa Soja, 2000. 70p. (Circular Técnica ${ }^{\circ}$ 30).

SILVA, F.A.C.; SILVA, J.J. da; DEPIERI, R.A.; PANIZZI, A.R. Feeding activity, salivary amylase activity, and superficial damage to soybean seed by adult Edessa meditabunda (F.) and Euschistus heros (F.) (Hemiptera: Pentatomidae). Neotropical Entomology, Piracicaba-SP, v. 41, n. 5, p. 386-390, 2012. DOI: 10.1007/s13744-012-0061-9.

SILVA, M. T. B.; CORRÊA-FERREIRA, B. S.; SOSAGOMÉZ, D. R. Erro e resistência. Revista Cultivar Grandes Culturas, Pelotas-RS, v. 8, n. 82, p. 22-25, 2006.

VILLAS BOAS, G. L.; GAZZONI, D. L.; OLIVEIRA, M. C. N.; COSTA, N. P.; ROESSING, A. C.; HENNING, A. A. Efeito de diferentes populações de percevejos sobre o rendimento e seus componentes, características agronômicas e qualidade de semente de soja. Londrina-PR: Embrapa Soja - CNPSO, 1990. 43 p. (Boletim de Pesquisa 1). 